\title{
ASSOCIATION OF MIDLINE DISCREPANCY WITH TEMPROMANDIBULAR JOINT DISORDER. A SYSTEMATIC REVIEW
}

\author{
SANDHYA JAIN ${ }^{1}$, NEETU SHARMA ${ }^{1}$, PALLAV PATNI ${ }^{2}$, DESHRAJ JAIN ${ }^{3}$
}

\author{
${ }^{1}$ Department of Orthodontics and Dentofacial Orthopedics, Government Dental \\ College, Indore, M.P., India \\ ${ }^{2}$ Department of Endodontics and Conservative Dentistry, Sri Aurbindo College of \\ Dentistry, Indore, M.P., India \\ ${ }^{3}$ Department of Prosthodontics, Government Dental College, Indore, M.P., India
}

\begin{abstract}
Aim. The aim is to evaluate the association between midline discrepancies and tempromandibular disorders (TMDs).

Methods. Literature search was performed by using various search engines to include human studies in English. TMDs include a wide variety of signs and symptoms such as pain in and around TMJ, jaw muscles, clicking and locking of jaws, pain during mandibular movement and restricted mandibular movements. The etiology is multifactorial, including one or several of the following factors like severe malocclusions (increased overjet, retroclination of incisors, cross bite, CR CO discrepancies etc), stress and psychological factors, structural abnormalities as possible etiology. There are controversies concerning the association between different traits of malocclusion and TMDs. The aim of the present study was to find out any association between signs and symptoms of TMDs with midline discrepancies, which represent an important trait of malocclusion.

Result. Of the seven studies evaluated in this systematic review for investigating the association between midline discrepancy and TMD, six had moderate grade (B) of evidence. Four studies of moderate grade evidence (B) showed a significant association between the presence of midline shift and TMDs, and the remaining studies (two) had non-significant association. Only one study had a strong grade of evidence (A) and interestingly it denies the presence of midline shift to be a causative factor for TMDs. So, it can be concluded that the results are inconclusive regarding the association of midline discrepancies with TMDs. Nonetheless, this requires concrete evidence which necessitates further long term research into this aspect.
\end{abstract}

Keywords: TMD, midline, asymmetry, systematic review

\section{Introduction}

Midline asymmetries require special consideration in orthodontic diagnosis and treatment planning, because orthodontists often treat patients with dental or facial midline shifts. Coincident midlines are an important aspect

Manuscript received: 28.06.2017

Received in revised form: 17.07.2017

Accepted: 24.07.2017

Address for correspondence: researchorthodontics@gmail.com of functional occlusion and are used as a clinical guide to establish ideal intercuspation. All three of the patient's midlines-facial, maxillary, and mandibular-must be considered for optimal correction. Midline correction should be undertaken since the beginning of treatment. These corrected midlines act as a guide for any further force systems used in completing the case.

Midline discrepancies can occur due to dental 
reasons, skeletal problems involving malpositioning of maxilla and/or mandible relative to the facial skeleton or due to functional shift. Functionally the midline can shift because of the presence of occlusal interferences leading to deflection of mandible [1]. Sheats et al. found noncoincident dental midline in $46 \%$ and maxillary midline deviation from the facial midline (39\%) [2], whereas Jain et al in 2015 found $77 \%$ midline deviation in routine clinical examination. Around $21 \%$ of patients showed upper dental midline shift, whereas $43 \%$ patients showed lower dental midline [1].

Malocclusion can be a hidden and in dormant condition predisposing to TMDs. Midline discrepancies in such cases indicate underlying important factors such as skeletal asymmetry, subdivision malocclusion and premature contacts. These factors have shown to be associated with TMDs and hence it becomes prudent to know about association between midline deviations and TMDs.

Any shift in the midline can disturb the seating of condyle in the glenoid fossa or apply unequal functional forces which can lead to disorders of the temporomandibular joint. Hence is it important to evaluate the predisposition of midline discrepancy in causing potential damage to the TMJ i.e. the temporo-mandibular disorders.

\section{Material and method}

The literature was searched using keywords such as Midline Discrepancies and Tempromandibular Joint Disorder or Craniomandibular Joint disorder (Table I). Review team of four persons made the searches. Various special databases like PubMed, Medline, Embase, Ovid were searched with the keywords. 13 studies were identified based on the results of the search. Additional 3 studies were included based on more extensive search. Flow Diagram shown in Figure 1represents the systematic search and selection strategy used in this study. Abstracts of these 16 papers were examined by at least two members, a full text of paper was obtained if it addressed the issue. The articles were evaluated independently by two persons who included evaluation of study design, study population, presence of control group, statistical test, and testing validity and reliability. In case of disagreement between them, the article was discussed among the whole group to reach the consensus. The included studies were judged for their quality. Out of 16 studies, 4 studies were excluded on the basis of exclusion criteria and one more study was rejected for being irrelevant to the issue (Table II). The remaining 11 relevant studies were analyzed for the evidence grade: 6 studies had moderate evidence (B), one study had strong grade of evidence (A) and remaining 4 studies were excluded due to limited evidence.

Inclusion criteria

- Human studies in English language addressing midline discrepancies in relation to signs and symptoms of TMD.

\author{
Exclusion Criteria \\ -Case reports \\ -Studies involving treatment group \\ -Cleft lip or palate \\ -Craniofacial Syndromes
}

Table I. Keywords for search strategies.

\begin{tabular}{|l|l|l|l|}
\hline Search Engines & Medline, PubMed, Embase, Ovid & NOT \\
& Midline & AND & Case report \\
Keywords & $\begin{array}{l}\text { Midline asymmetry } \\
\text { Cidline Discrepancies } \\
\text { Craniomandibular Disorder } \\
\text { Tempromandibular Disorders } \\
\text { Tempromandibular Joint Disorders } \\
\text { Tempromandibular joint Dysfunction Syndrome }\end{array}$ & \\
\hline Limits: & \multicolumn{3}{|l|}{$\begin{array}{l}\text { Tuman Studies Only } \\
\text { English Language Only }\end{array}$} \\
\hline
\end{tabular}

Table II. Excluded studies from the search.

\begin{tabular}{|l|l|}
\hline Study & Reason for low evidence \\
\hline Fushima et al. (1999) [3] & Small sample size with no control group. \\
\hline Costea et al. (2016) [4] & No midline evaluation \\
\hline Sipil et al. (2006) [5] & High dropout rate, age is not specified \\
\hline Boer et al. (1997) [6] & Small sample size, not relevant study \\
\hline Thilander. (2002) [7] & Not relevant \\
\hline
\end{tabular}




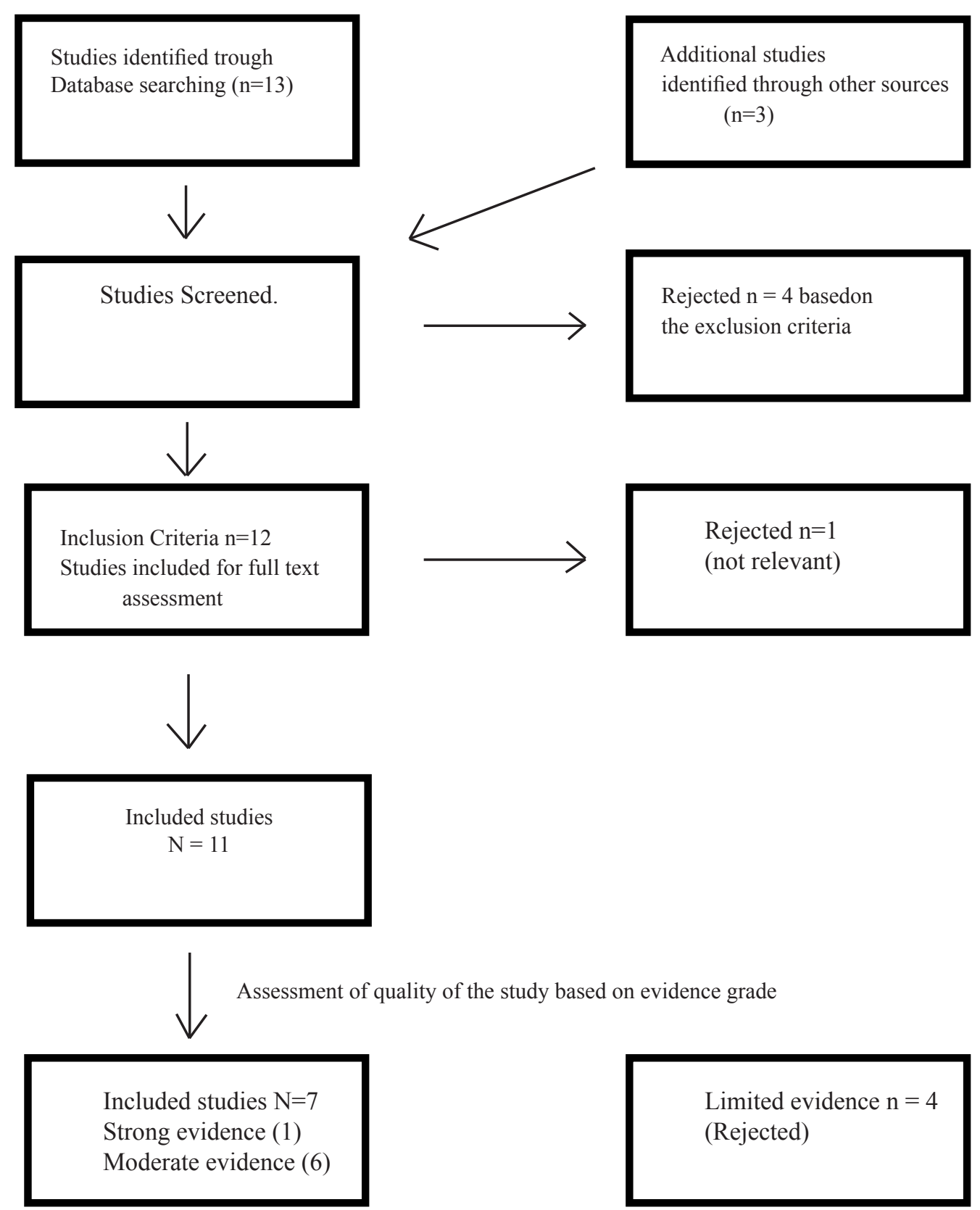

Figure 1. Flow diagram for systematic search and selection strategy.

Setting the Evidence Grade [8]

Strong evidence A

- RCT, prospective studies

- Large sample size

- Well defined control group

- Low dropout rate

- Relevant statistical analysis

Moderate evidence B

- Prospective studies, control clinical trial, cohort study

- Large sample size

- Well defined control group
- Low dropout rate

- Relevant statistical analysis

Limited evidence $\mathrm{C}$

- Cross sectional study

- High dropout rate

- No control group

- Limited or no statistical analysis

- Addressing the issue in question only in part.

Evaluation for conclusion [8]

Evaluation based on the grade of evidence is presented in Table III. Conclusion based on at least two studies with strong evidence considered strong scientific 
grade 1 evidence.

Conclusion based on one study with strong evidence and two with moderate-strong evidence were considered moderately strong scientific support for grade 2 evidence. Studies with opposite conclusions lower the grade of evidence.

Conclusions based on two studies with moderately strong evidence were considered moderately scientific support or grade 3 evidence. If opposite conclusion studies existed, the scientific evidence was considered as insufficient and contradicting.

Insufficient scientific support means lack of studies with evidence criteria.

Contradicting scientific support means contradictory results exist between similar evidence studies. The scientific result was considered contradictory because no conclusions could be drawn.

\section{Results}

Out of 16 studies 4 were excluded as they were not relevant to questionnaire at hand. Out of 12 studies, after analyzing the full text, one was rejected as being not relevant. Then of the final 11 studies evaluated for evidence, 4 studies were not included on the basis of their limited evidence; 6 studies were of moderate grade of evidence (B) and only one study had strong grade of evidence (A). The results of the selected studies are explained in Table IV.

Table III. Evaluation for conclusion.

\begin{tabular}{|l|l|}
\hline Grade of Evidence & Criteria \\
\hline Grade 1 Evidence & Two studies with strong evidence \\
\hline Grade 2 Evidence & One study with strong evidence and two studies with moderate evidence \\
\hline Grade 3 Evidence & Two studies with moderate evidence \\
\hline Insufficient Scientific support & Lack of studies with evidence \\
\hline
\end{tabular}

Table IV. Results of studies included in the systematic review.

\begin{tabular}{|c|c|c|c|c|c|c|}
\hline Study & Study Design & Population & Age & Variables & $\begin{array}{l}\text { Result } \\
\text { (Association } \\
\text { between } \\
\text { Midline and } \\
\text { TMDs) }\end{array}$ & Evidence \\
\hline Sonneson (1998) [9] & $\begin{array}{l}\text { Prospective } \\
\text { study }\end{array}$ & $\begin{array}{l}104 \text { (Danish } \\
\text { population) }\end{array}$ & $7-13 \mathrm{yr}$ & $\begin{array}{l}\text { Midline } \\
\text { discrepancy as one } \\
\text { of the variable }\end{array}$ & Significant result & B \\
\hline Pullinger (1993) [10] & $\begin{array}{l}\text { Prospective } \\
\text { Study }\end{array}$ & $\begin{array}{l}147 \text { control } \\
413 \text { cases }\end{array}$ & Age not given & $\begin{array}{l}\text { Midline } \\
\text { discrepancy as one } \\
\text { of the variable }\end{array}$ & $\begin{array}{l}\text { Non Significant } \\
\text { result }\end{array}$ & A \\
\hline Almasan (2011) [11] & $\begin{array}{l}\text { Prospective } \\
\text { Study }\end{array}$ & $\begin{array}{l}64 \text { subjects } \\
24 \text { TMD } \\
40 \text { Control }\end{array}$ & Over 18 years & $\begin{array}{l}\text { Midline } \\
\text { discrepancy as one } \\
\text { of the variable }\end{array}$ & $\begin{array}{l}\text { Significant } \\
\text { Result }\end{array}$ & B \\
\hline Pradham (2002) [12] & $\begin{array}{l}\text { Prospective } \\
\text { Study }\end{array}$ & $\begin{array}{l}50 \text { female, } 25 \\
\text { Cases, } \\
25 \text { Control }\end{array}$ & $\begin{array}{l}\text { Average Age } 31- \\
28 \text { years in TMJ } \\
\text { Group, } 30 \text { years } \\
\text { for all Subject }\end{array}$ & $\begin{array}{l}\text { Midline } \\
\text { discrepancy as one } \\
\text { of the variable }\end{array}$ & Significant result & B \\
\hline Celic (2002) [13] & $\begin{array}{l}\text { Prospective } \\
\text { study }\end{array}$ & $\begin{array}{l}230 \text { Subject } \\
\text { Questions }+ \\
\text { Clinical study }\end{array}$ & $19-28$ & $\begin{array}{l}\text { Midline } \\
\text { discrepancy as one } \\
\text { of the variable }\end{array}$ & $\begin{array}{l}\text { Non Significant } \\
\text { result }\end{array}$ & B \\
\hline Ballanti (2013) [14] & $\begin{array}{l}\text { Prospective } \\
\text { study }\end{array}$ & $\begin{array}{l}580 \text { subjects } \\
229 \text { males and } 301 \\
\text { females }\end{array}$ & $\begin{array}{l}\text { Mean age }-13 \\
\text { yrs }\end{array}$ & $\begin{array}{l}\text { Midline } \\
\text { discrepancy as one } \\
\text { of the variable }\end{array}$ & Significant result & B \\
\hline Padala (2012) [15] & $\begin{array}{l}\text { Case-Control } \\
\text { Study }\end{array}$ & $\begin{array}{l}40 \text { Subjects } \\
\text { grouped into } \\
\text { symptomatic and } \\
\text { asymptomatic } \\
\text { group }\end{array}$ & $\begin{array}{l}\text { Age group }-15 \\
-35 \mathrm{yrs}\end{array}$ & $\begin{array}{l}\text { Midline } \\
\text { discrepancy as one } \\
\text { of the variable }\end{array}$ & $\begin{array}{l}\text { Non Significant } \\
\text { Result }\end{array}$ & B \\
\hline
\end{tabular}




\section{Discussion}

Large overjet and deep overbite have been associated with signs and symptoms of temporomandibular disorders. Our study was performed to investigate the association of midline discrepancy with the temporomandibular disorders. After following the protocols of the search strategies, 7 related articles were finally selected and extensively analyzed in terms of type of study, population, age criteria, variables studies, result and evidence grade of the study. Six out of seven study (Sonneson 1998, Almasan 2011, Pradhan 2002, Celic 2002, Ballanti 2013 and Padala 2012) had moderate grade of evidence and one study (Pullinger 1993) had strong grade of evidence. In all the articles, midline was a part of the occlusal or malocclusion traits studied.

Sonneson et al. [9] in 1998 studied the traits of malocclusion and TMD in 104 subjects of Danish population between the age group of 7-13 yrs. Out of the complete sample only 13 subjects had midline discrepancy and found that $46.2 \%$ of the children with midline displacement of $>$ $2 \mathrm{~mm}$ had TMD trait based on screening and Helkimo's indices.

Pullinger et al. [10] in 1993 performed a prospective study on 413 cases with 147 being in the control group. On performing the logistic regression, the authors concluded that midline discrepancy was not a predictor of TMD in adult patients. This study falls in the grade A of strong evidence study and fails to establish any association between the midline shift and TMDs.

Almasan et al. [11] in 2011in their prospective study on 64 subjects (24 TMD and 40 control) over 18 years of age, evaluated midline and found significant result in the presence of TMD and midline shift in Class I malocclusions ( $p$ value -0.04 ). In Class II and Class III subjects it was not significant, $p$ value -0.159 and 0.226 respectively.

Pradham et al. [12] in 2002 in their prospective study involving 50 females, 25 study and 25 control with average age of 30 years concluded that the frequency of midline deviation in the TMJ group, 92\% (23 versus 2 with no deviation) was significant that $24 \%$ in control group (6 versus 19 no deviation) $(\mathrm{p}-<0.001)$.

Celic [13] in 2002 evaluated 230 subjects in the age group of 19-28 years in their prospective study and concluded that midline discrepancy $>2 \mathrm{~mm}$ influenced the prevalence of TMJ clicking and mandibular deviation(p$0.007)$. The authors found a weak correlation between the presence of midline shift and TMDs.

Ballanti et al. [14] in 2013 evaluated 580 subjects (229 males and 301 females) between 6-11 years and 1216 years old age group. The sample was divided into 6 groups. The table for each group was not shown and only the prevalence in percentage was calculated. The authors concluded that the prevalence of TMD was $15 \%$ among subjects who had no midline deviation, $15.8 \%$ among subjects who had a functional deviation and $4.7 \%$ among subjects who had anatomic deviation $(\mathrm{p}-0.05)$

Padala et al. [15] in 2012 performed a case-control study with 40 subjects in symptomatic and asymptomatic group of TMDs. The dental midlines were coincident at CR and $\mathrm{CO}$ in $15 / 20(75 \%)$ asymptomatic subjects and in 10/20 (50\%) symptomatic subjects. The Chi-square test showed statistically non significant results. The mean midline shift from $\mathrm{CO}$ to $\mathrm{CR}$ in asymptomatic subjects was $0.89 \pm 0.55$ $\mathrm{mm}$ and $0.96 \pm 0.65 \mathrm{~mm}$ in symptomatic subjects $(\mathrm{P}=0.751$; statistically non significant).

Of the total seven studies discussed in this article, four studies showed a significant correlation between the presence of midline shift and TMDs and the remaining three had non-significant correlation. Of the three studies, which showed negative association, one had strong grade of evidence (A) and other two had moderate grade of evidence (B). This negates the possibility of believing midline to cause disorders of the TMJ, since strong grade evidence study is against it. However, it is necessary to perform long term prospective evaluation to reach a final conclusion.

\section{Conclusion}

The scientific evidence is insufficient and contradictory for this study evaluating the association between midline and TMDs. Clear and sound evidence cannot be verified and there is still need for further long term studies.

\section{References}

1. Jain S, Jain V, Gupta A. Prevalence of midline shift in orthodontic patients. International Journal of Current Innovation Research. 2015;1(10):287-290.

2. Sheats RD, McGorray SP, Musmar Q, Wheeler TT, King GJ. Prevalence of orthodontic asymmetries. Semin Orthod. 1998;4(3):138-145.

3. Fushima K, Inui $M$, Sato $S$. Dental asymmetry in temporomandibular disorders. J Oral Rehabil.1999;26:752-756.

4. Costea CM, Badea ME, Vasilache S, Mesaroş M. Effects of CO-CR discrepancy in daily orthodontic treatment planning. Clujul Med.

2016;89(2):279-286.

5. Sipilä K, Ensio K, Hanhela H, Zitting P, Pirttiniemi P, Raustia A. Occlusal Characteristics in subjects with facial pain compared to a pain-free control group. Cranio. 2006;24(4):245-251.

6. de Boer M, Steenks MH. Functional unilateral posterior crossbite. Orthodontic and functional aspects. J Oral Rehabil. 1997;24:614-623.

7. Thilander B, Rubio G, Pena L, de Mayorga C. Prevalence of temporomandibular dysfunction and its association with malocclusion in children and adolescents: an epidemiologic study related to specified stages of dental development. Angle Orthod. 2002;72(2):146-154.

8. Mohlin B, Axelsson S, Paulin G, Pietilä T, Bondemark $\mathrm{L}$, Brattström V, et al. TMD in relation to malocclusion and orthodontic treatment. Angle Orthod. 2007;77(3):542-548.

9. Sonnesen L, Bakke M, Solow B. Malocclusion traits and symptoms and signs of temporomandibular disorders in children with severe malocclusion. Eur J Orthod. 1998;20(5):543-559. 


\section{Dental Medicine}

10. Pullinger AG, Seligman DA, Gornbein JA. A multiple logistic regression analysis of the risk and relative odds of temporomandibular disorders as a function of common occlusal features. J Dent Res. 1993;72(6):968-979.

11. Almăşan OC, Băciuţ M, Almăşan HA, Bran S, Lascu L, Iancu $\mathrm{M}$, et al. Skeletal pattern in subjects with temporomandibular joint disorders. Arch Med Sci. 2013;9(1):118-126.

12. Pradham NS, White GE, Mehta N, Forgione A. Mandibular deviations in TMD and non-TMD groups related to eye dominance and head posture. J Clin Pediatr Dent. 2001;25(2):147-155.
13. Celić R, Jerolimov V, Pandurić J. A study of the influence of occlusal factors and parafunctional habits on the prevalence of signs and symptoms of TMD. Int J Prosthodont. 2002;15(1):43-48. 14. Ballanti F, Ranieri S, Baldini A, Pavoni C, Bollero P, Cozza P. Gnathological features in growing subjects. Ann Stomatol (Roma). 2014;4(3-4):230-238.

15. Padala S, Padmanabhan S, Chithranjan AB. Comparative evaluation of condylar position in symptomatic (TMJ dysfunction) and asymptomatic individuals. Indian J Dent Res. 2012 JanFeb;23(1):122. . 